\title{
PERCURSOS E INOVAÇÕES: A UFTM E O USO DOS 20\% A DISTÂNCIA NO ENSINO PRESENCIAL NO PERÍODO 2010-2012
}

\author{
PATHWAYS AND INNOVATIONS: UFTM AND THE USE OF THE 20\% IN \\ DISTANCE IN FORMAL EDUCATION IN THE PERIOD OF 2010-2012
}

\author{
Diogo Silva Chagas ${ }^{1}$ \\ Martha Maria Prata-Linhares ${ }^{2}$
}

\begin{abstract}
RESUMO
As tecnologias digitais tem aberto um novo espaço de aprendizagem facilitando a promoção de uma nova gestão de tempo e espaço no Ensino Superior. O artigo trata de uma pesquisa que teve como objetivo investigar a realização dos $20 \%$ da carga horária na modalidade a distância das disciplinas presenciais na Universidade Federal do Triângulo Mineiro (UFTM) nos dois anos posteriores ao período de implantação do ambiente de aprendizagem virtual institucional, de 2010 a 2012. A abordagem da pesquisa tem caráter qualiquantitativo com pesquisa bibliográfica, documental e de campo.
\end{abstract}

Palavras-chave: Tecnologias de informação e comunicação. Professor universitário. EAD. Educação superior.

\section{ABSTRACT}

Digital technologies have opened a new learning space facilitating the promotion of a new management of time and space in Higher Education. This paper discusses an investigation that aimed to investigate how the use of the $20 \%$ of the credit hour in distance education modality of the live-class disciplines was held at the Federal University of Triangulo Mineiro in the two following years after the implementation of the institutional virtual learning environment, from 2010 to 2012. The research approach has a qualiquantitative nature with a bibliographic, documental and field research.

Key-words: Information and communication technologies. University professor. Distance education. Higher education.

\section{INTRODUÇÃO}

"Nossos alunos mudaram radicalmente. Os alunos de hoje não são mais as pessoas que nosso sistema educacional foi projetado para ensinar"

Marc Prensky

\footnotetext{
1 Mestrando do Programa de Pós-Graduação em Linguística da Universidade Federal de São Carlos (PPGL/UFSCar) E-mail: chagasdiogos@gmail.com

${ }^{2}$ Docente do Programa de Pós-Graduação em Educação. Universidade Federal do Triângulo Mineiro UFTM.E-mail: martha.prata@gmail.com
} 
Engajados e preocupados com os novos rumos da educação, tendo em vista as mudanças no contexto educacional, levando em conta a Educação a Distância (EAD) e a possibilidade do uso de recursos da internet na educação, o texto que segue visa traçar desde uma trajetória da EAD no Brasil e no mundo, perpassando por questões que se referem a inovação e entrada e uso de tecnologias de informação e comunicação (TIC) na Instituição de Ensino Superior pesquisada.

Embasados nas legislações vigentes que regulamentam a EAD no Brasil e que normalizam o uso de $20 \%$ a distância no ensino presencial, a ideia central é a de análise do contexto educacional da Universidade Federal do Triângulo Mineiro (UFTM), levando em consideração como a EAD é vista pela instituição e como se instala, bem como a inclusão das TIC nos currículos e projetos pedagógicos dos cursos no período pesquisado que compreende o ano de 2010 a 2012.

\section{A EAD no Brasil e no mundo}

Alheia a ideia de que a Educação a Distância é de caráter inovador, essa modalidade de ensino não é totalmente inovadora. O que tem acontecido é o uso das tecnologias da informação e comunicação (TIC) no contexto de ensino-aprendizagem, podendo, ou não, tornar-se de caráter inovador. Maia e Mattar (2007, p. 21) salientam que “a partir da invenção da escrita, a comunicação liberta-se no tempo e no espaço", e possibilita que a educação se dê a distância, uma vez que, anterior a isso, a educação só se dava sincronicamente num mesmo tempo e espaço, apenas pela oralidade. Essa escrita, de acordo com Maia e Mattar (2007, p. 21), vem desde os desenhos em pedras feitos pelas sociedades primitivas e que, com a invenção da imprensa, obteve maior ascensão para que se fossem disseminadas as informações e os registros importantes, sendo válido ressaltar que até então o propósito não era focado na educação.

É preciso sobressaltar que, no que se refere às tecnologias, conforme aponta Kenski (2012, p. 18), tratam-se de um "conjunto de conhecimentos e princípios científicos que se aplicam ao planejamento, à construção e a utilização de um equipamento em um determinado tipo de atividade nós chamamos de "tecnologias"”. Ou seja, a ideia de tecnologia voltada apenas para os computadores, televisores ou rádios é errônea, uma vez que somos circundados de várias tecnologias que são tão costumeiras que não a percebemos mais como "não naturais". 
Por isso, considerar a década de 10 do século XXI como sendo uma "era tecnológica" não se valida, pois há tecnologia desde o começo da civilização, bem como apontado por Kenski (2012, p. 19). A autora ainda pontua que a transição humana é toda permeada de tecnologias culturalmente contemporâneas.

Em verdade, a educação a distância já é conhecida por outras denominações como “"estudo por correspondência', 'estudo independente', 'telecursos', 'autoinstrucional', etc.”, o que muda são suas metodologias e técnicas de ensino que foram sendo adaptadas aos meios em que se dava a educação (KENSKI, 2012, p. 219-220).

Dividida em três gerações, descritas por Maia e Mattar (2007, p. 21), a EAD teve sua primeira fase com cursos por correspondências, que consistiam unicamente em materiais impressos e enviados por correio. De acordo com Nunes (2009, p. 2), o primeiro registro de ensino a distância foi em 1728, quando Caleb Philips anunciou em jornal suas aulas ministradas por correspondência. Em uma segunda fase, surge a Open University no Reino Unido, que, de acordo com Nunes (2009, p. 6), emergiu, no ano de 1969, da ideia de que a televisão pudesse ser integrada à educação incisivamente de forma a mobilizar grandes massas e incorporá-las.

Após a abertura da Open University, a ideia se difundiu pelo mundo e foi propulsora para novos pensamentos e olhares para a EAD. A terceira fase, definida por Maia e Mattar (2007, p. 22), se refere a EAD online que inclui recursos de multimídia, computador, internet, hipermídias e, posteriormente, como salienta Mattar (2011, p. 3), a web 2.0 e as redes sociais. Essas TIC, assim como frisa Nunes (2009, p. 7), podem gerar uma condição de interação por meios não lineares, se contrastando a como o modelo tradicional propõe, dando uma maior abertura para a flexibilidade do estudante quanto ao seu ritmo, velocidade e percursos.

Nos últimos anos chegou o termo "web 3.0", que surge para:

unir, integrar e analisar dados de vários conjuntos de dados para obter uma nova
corrente de informação. É capaz de melhorar o gerenciamento de dados, suportar
acessibilidade da internet móvel, simular criatividade e inovação, incentivar fator
do fenômeno de globalização, aumentar a satisfação do cliente e ajudar a
organizar a colaboração na web social (AGHAEI et al, 2012, p. 3, tradução
nossa)

$\mathrm{Na}$ educação, aparece um viés diferente, em que essa "educação 3.0" é, como coloca Movarec (2008, s/p, tradução nossa), "socialmente construída e contextualmente reinventada", ou seja, a educação está em todo lugar através da tecnologia, o aluno aprende não só com o professor, mas com cada pessoa que tenha o que ensinar, num sistema de 
construção colaborativo e a escola passa a ser vista pelos pais como um lugar relevante para o aprendizado dos filhos, não apenas como creches, forma com que é vista até então.

Fato interessante a ressaltar é que antes da internet a única fonte de consulta à história era por meio de livros, que por vezes registravam apenas fatos grandiosos e não eram comuns informações do dia-a-dia que se tem atualmente (SOALHEIROS, 2006, p. 40). Hoje, com o buscador Google obtêm-se informações das mais variadas em questão de segundos.

Direcionando o olhar para a EAD no Brasil, pode-se destacar o Brasil como um dos principais países presentes no desenvolvimento da EAD até os anos 70, assim como coloca Alves (2009, p. 9), que diz que "pouco antes de 1900, já existiam anúncios em jornais (...) oferecendo cursos profissionalizantes por correspondência", com envio de materiais didáticos via correios, sendo única modalidade até por volta de 1920.

O que revolucionou o caráter educacional a distância no Brasil foi a iniciativa de transmissão de programas educativos via rádio que visava que a educação chegasse a toda população, e a proposta obteve sucesso. A EAD no Brasil esteve no ranking dos principais desenvolvedores de EAD. Porém, como Alves explica (2009), na década de 1970 houve uma queda devido ao desmonte da rádio como EAD

Diferentemente do cinema, que não teve um marco histórico específico que representasse sua contribuição na EAD, a TV educativa criada em 1967, foi uma iniciativa bem sucedida, principalmente nas décadas de 1960 e 1970. O Ministério das Comunicações decretou, inclusive, tempo obrigatório e gratuito em que as emissoras comerciais deveriam se dedicar à educação.

Com a chegada dos computadores e o advento da internet surgiu a possibilidade de criar redes sociais para interação síncrona e assíncrona, em que o conhecimento é colaborativo e todos os agentes envolvidos ganham caráter de produtor, e como ressalta Mattar (2011), sem os antigos estereótipos de professor-conhecedor e aluno-receptor.

Essas interações síncronas e assíncronas se diferem no sentido de que a primeira se refere a atividades online que são propostas para serem realizadas, em tempo real, mesmo que espacialmente distantes, sendo a sala de bate-papo um exemplo para tal, onde se pode encontrar professor e aluno criando um ambiente de interação num mesmo dado tempo em um espaço virtual. As interações assíncronas não têm todos os envolvidos conectados ao mesmo tempo, sendo emails, fóruns e grupos exemplos para a interação assíncrona, podendo cada indivíduo do processo estar conectado em tempos diferentes. 
No que concerne a questão educacional, Valente $(2009$, p. 38) destaca que a distância temporal praticamente se anula, uma vez que, com o uso da internet e seus aplicativos, o professor pode orientar e transmitir informações para o aluno de forma sincrônica.

Do ponto de vista do físico, apesar de haver distanciamento espacial, Valente $(2009$, p. 38) pontua o estar junto virtual, termo cunhado pelo próprio autor, que devido à interação faz com que o distanciamento seja praticamente imperceptível. O espaço físico, nessa perspectiva, dá lugar para o que Levy (1998) chama de ciberespaço ou também para o que Harasim (2005) chama de redes de aprendizagem.

Moran (2007, p. 132) pontua um fator muito importante para a questão da EAD no Brasil, considerando o brasileiro "aberto à adoção de novas tecnologias", o que facilitou a difusão e implementação da EAD no Brasil.

Feito esse breve percurso histórico, retomamos a concepção distorcida de que a EAD é inovadora e firmamos que, no que se refere à EAD, as tecnologias que a circundam são condizentes à sociedade e cultura contemporâneas, o que confirma a ideia pontuada por Kenski (2012), de que a sociedade é permeada de tecnologias condizentes a seu tempo, e essa inovação a que se refere acompanha a cultura tecnológica do período juntamente com a forma que o professor consegue discernir quais tecnologias contribuem no processo de ensino e de aprendizagem e a forma com que ele conduz esse processo.

\section{Os 20\% EAD: conceitos e legislação}

Primeiramente, é preciso conceituar o que vem a ser a Educação a Distância, ou EAD, que, seguindo a definição dada por Moran (1994, p.1), "é o processo de ensinoaprendizagem, mediado por tecnologias, no qual professores e estudantes estão separados espacial e/ou temporalmente". O autor ainda destaca o que difere "educação" de "ensino a distância", sendo este mais voltado para o papel do professor, e "educação" abrange muito mais conceitos que circundam a questão (MORAN,1994, p,1)

Nos documentos que legislam a Educação a Distância no Brasil, de acordo com o artigo $1^{\circ}$ do Decreto, temos que se trata de:

modalidade educacional na qual a mediação didático-pedagógica nos processos de ensino e aprendizagem ocorre com a utilização de meios e tecnologias de informação e comunicação, com estudantes e professores desenvolvendo atividades educativas em lugares ou tempos diversos. (BRASIL, 2005) 
Como dito anteriormente, conforme Valente (2009), a questão do espaço e tempo levam à questão do "estar-junto-virtual", ou seja, a ideia de distanciamento é quase nula devido à interação professor-aluno via internet e seus aplicativos.

Tendo em mente o que define a EAD, ressaltemos as legislações vigentes que regem a EAD e regulamentam como modalidade de ensino formal e oficializada. A educação a distância no Brasil foi normalizada pela LDB (Lei de Diretrizes e Bases da Educação Nacional) em dezembro de 1996, em seu Art. 80, da Lei $\mathrm{n}^{0}$ 9.394, e regulamentada em fevereiro de 2005, pelo Decreto n. ${ }^{0} 5.622$.

Lobo Neto (2011, p. 402) pontua que antes dessa regulamentação a EAD era tratada como experimental e para que pudesse ser executada era preciso receber pareceres dos Conselhos Federal e Estaduais para que pudesse ser colocada em prática, complementando que somente após a promulgação da Lei 9.394 é que a EAD passou ser “alternativa regular" em todo o Brasil. Entretanto, para que a instituição de ensino superior possa oferecer cursos EAD é preciso que ela possua um credenciamento junto ao MEC.

Contudo, a educação a distância ainda é alvo de mitos e algumas mistificações sobre sua ineficiência e por ser considerada, por alguns, como alternativa para desfazer a impressão de que há classes excluídas sem acesso à educação, conforme diz Lobo Neto (2011, p. 406).

\begin{abstract}
Como todas as ressalvas aos preconceitos, avança-se na concepção de que, mais do que uma delimitação de campos entre EAD e educação presencial, o processo de mudança nos paradigmas da comunicação está promovendo uma educação que se vale de presença física e virtual, no contexto de um projeto pedagógico de qualidade. Cada vez mais perde o sentido a distinção dicotômica do "presencial" e "a distância" (LOBO NETO, 2011, p. 408)
\end{abstract}

É nesse viés de não distinção extremista entre presencial e a distância que entrou, então, a questão do ensino presencial com $20 \%$ da carga horária a distância. A implantação dos $20 \%$ a distância "regulamenta a introdução de disciplinas no modo semipresencial", pontua Farias (2011, p. 447), de acordo com a Portaria do Ministério da Educação no 4.059 .

Carlini e Tarcia (2010, p. 17) salientam que essa "semipresencialidade é caracterizada, nesse instrumento legal, pela realização de atividades e situações educativas a distância e, portanto, utilizando tecnologias específicas".

A ideia central é a de que, dessa forma, sejam realizadas atividades, previamente planejadas, que sejam realizadas com distância tanto física quanto temporal entre professor 
e aluno, sendo que muitas vezes os $20 \%$ a distância acabam sendo uma complementação do construído em sala de aula: "o eixo principal continua sendo o da sala de aula, e o eixo complementar e inovador será definido pelo uso de tecnologias de educação a distância" (CARLINI e TARCIA, 2010, p. 19).

Poderão ser ofertadas as disciplinas referidas no caput, integral ou parcialmente, desde que esta oferta não ultrapasse $20 \%$ (vinte por cento) da carga horária total do curso (MEC, PORTARIA 4.059).

Moran (2007, p. 128) destaca que o ensino semipresencial tem a tendência de progredir, uma vez que é mais adaptável à nova sociedade que é totalmente conectada, crianças e jovens já são familiarizados com a internet, rede, celular e multimídias muito mais que os adultos.

O autor também chama atenção para a resistência à implantação dos $20 \%$ a distância nas universidades. Moran (2007) explica que os $20 \%$ são aplicados apenas a disciplinas como recuperação ou disciplinas comuns a todos os cursos, como, por exemplo, metodologia científica.

É possível confirmar tais considerações pelos dados levantados em análise dos projetos político-pedagógicos no período 2010-2012 dos cursos da instituição pesquisada, pois, nestes projetos, somente estão previstas atividades a distância, por meio da plataforma Moodle, apenas nas disciplinas EDP (Estudo e Desenvolvimento de Projetos) e TCC (Trabalho de Conclusão de Curso), o que mostra ainda o pouco uso de um ambiente virtual de aprendizagem em disciplinas regulares de conhecimento específico do curso. Porém, também notou-se que, apesar das atividades a distância não estarem presentes nos projetos político-pedagógicos dos cursos, alguns planos de disciplinas já fazem menção aos uso dos 20\% a distância. Assim, percebe-se que estamos tratando de um campo que vem mudando rapidamente e em que as mudanças vem acontecendo antes de serem oficializadas.

\section{O que muda na prática docente?}

Antes mesmo de dissertar o que muda na prática docente, é preciso saber do que se trata essa prática, o que é ser professor, bem como discorrer sobre o que vem a ser a inovação. O professor muitas vezes é visto "como um sujeito que tem um conhecimento específico e quer passar esse conhecimento para alguém", assim como coloca Prata- 
Linhares (2011, p. 99) após uma busca dos significados da própria palavra professor em dicionários, que se difere das outras profissões que indicam ser advindas de algum curso específico (médico - Medicina; engenheiro - Engenharia, etc.), enquanto que para o professor não fica claro que é necessária uma formação específica.

Nesse sentido, Souza e Guimarães (2011, p 26) completam essa ideia dizendo que "o professor é um profissional cujo espaço principal de trabalho é o ensino", ressaltam ainda uma questão do baixo status do ensino no meio acadêmico, o qual o professor vale pela pesquisa, não pelo ensino, considerando o tripé que fundamenta uma universidade: ensino, pesquisa e extensão.

Ainda assim, em meio a essas questões que envolvem o próprio fato do ser docente, o professor tem de estar apto a acompanhar as mudanças socioculturais e ser inovador dentro daquilo que lhe é acessível, o que faz com que uma formação para ser professor seja fundamental para esse embasamento teórico-prático do professor, permitindo que seu olhar ultrapasse o simples repasse de informação para atingir o aluno de forma que esse aluno se engaje para construir o conhecimento.

Já no que se refere à inovação, o conceito que se circunda sempre veio atrelado às tecnologias. Entretanto, é necessário chamar atenção para que o que se entende por inovação, na educação, envolve novos conceitos, organização curricular, práticas educativas, planejamento de gestão, as novas tecnologias e as novas formas de entender o conhecimento. Sendo assim, inovação se relaciona à mudança, resultado do desejo e da ação de inovar em busca de novas respostas dentro do contexto educacional (PRATALINHARES, 2012). Assim, as tecnologias por si só não são inovadoras.

O pensamento que norteia para tais mudanças educacionais deve partir desde a equipe gestora até o corpo discente, incorporando tais medidas para inovação e implantação da semipresencialidade. Behrens (1996, apud MASETTO, 1998, p. 67), mesmo tendo passado mais de 20 anos de sua afirmação, ainda é atual ao discorrer sobre o fato de os tempos terem mudado e as práticas pedagógicas estarem, ainda, ultrapassadas para o que se espera numa sociedade que tem se renovado diariamente.

Para tal, as mudanças que ocorrem na prática docente devem ser guiadas pelo pressuposto de que é preciso mudar percepções e não só as teorias. Conforme aponta Kenski (2003), é preciso compreender as novas abordagens do mundo, da cultura, da sociedade. É preciso que os professores resistam à tentação de se levar em linhas retas, sem ignorar as tendências (MASETTO, 1998). 
Masetto (2004) elenca alguns aspectos importantes ao se pensar na inovação na universidade:

\begin{abstract}
- a re-organização e flexibilização curricular para atender às novas exigências do projeto pedagógico ou de novas metas educacionais; (...) - a substituição da metodologia tradicional, baseada apenas em aulas expositivas, por metodologias que favoreçam o alcance dos vários objetivos educacionais, estimulem o aluno para aprender e possibilitem sua participação no processo de aprendizagem; - a exploração das novas tecnologias, baseadas na informática, telemática, internet, propiciando atividades a distância, fora do espaço sala de aula, ao mesmo tempo estimulando o aluno para o encontro com o professor e os colegas; (...) - a substituição do papel do professor de ministrador de aulas e transmissor de informações para o papel de mediador pedagógico. (MASETTO, 2004, p. 197198)
\end{abstract}

Ao falar em inovação e práticas docente outro fator importante a ser pensado é o de que os alunos de hoje são, em sua maioria, "nativos digitais" (PRENSKY, 2001). De acordo com o autor, são nativos digitais porque "os alunos de hoje representam a primeira geração que cresceu junto com as novas tecnologias, (...) eles passaram toda a vida circundados de computadores, videogames, celulares, (...)" (p. 1, tradução nossa). Paralelos aos nativos, o autor coloca os imigrantes digitais ${ }^{\mathrm{ii}}$, considerando-os como sendo os que não nasceram e cresceram envoltos de tecnologias, mas em algum momento se fascinaram à elas e adoraram muito das novas tecnologias.

Como dito anteriormente, as tecnologias mudam em concomitância à sociedade. Assim, é preciso unir tais informações e engajar em novas reflexões acerca do sistema educacional. De acordo com as palavras de Masetto (1998), nos últimos anos vivemos em uma sociedade caracterizada como sendo a sociedade da informação. Werthein (200, p. 71), ao falar da sociedade da informação, explica que "a expressão "sociedade da informação" passou a ser utilizada, nos últimos anos desse século, como substituto para o conceito complexo de "sociedade pós-industrial" (...)".

De acordo com Kensky (2012) hoje o que se desloca é a informação, e acontece em dois sentidos:

o primeiro, o da espacialidade física, em tempo real, sendo possível acessá-la por meio das tecnologias midiáticas de última geração. O segundo, por sua alteração constante, pelas transformações permanentes, por sua temporalidade intensiva e fugaz (KENSKI, 2012, p. 30)

Considerar como sendo sociedade da informação implica em novos desafios impostos aos profissionais, no geral, que partem desde a aceitação da combinação seu trabalho com o dos outros, que se predisponham a tarefas cada vez maiores e que estejam aptos às mudanças (MASETTO, 1998). Kenski (2012) também lembra que novos ritmos e 
dimensões no ensinar e aprender são impostos devido às rápidas transformações tecnológicas da atualidade.

\section{A UFTM e a Inovação Tecnológica no Contexto Educacional}

Como foi possível perceber até agora, as tecnologias acompanham a sociedade e a cultura contemporânea a elas. Buscando perceber como a Universidade Federal do Triângulo Mineiro, antiga Faculdade de Medicina do Triângulo Mineiro, tem se desenvolvido no sentido de inovações tecnológicas em contexto educacional, foi feito um breve apanhado histórico da instituição e que resultou em achados importantes que contextualizam o engajamento da UFTM no que se refere ao uso das TIC.

Para coletar informações a respeito desta época, realizou-se uma entrevista Dalva Pereira da Silva (2012), profissional que atuava na universidade neste período.

De acordo com a entrevistada, que, em 1988, integrava uma equipe de profissionais da Universidade Federal do Triângulo Mineiro, na época Faculdade de Medicina do Triângulo Mineiro (FMTM), que criou a Rede MEDNET/FMTM. Essa rede visava congregar profissionais e entidades ligadas à área da saúde através de um Sistema de Tratamento de Mensagens (STM-400) da Embratel, com intuito de compartilhar serviços e fazer um intercâmbio de informações e conhecimentos.

O serviço era disponível nacionalmente, sendo que a coordenação, bem como a iniciativa, era de responsabilidade da FMTM. Silva (2012) explicou que o objetivo principal da Rede MEDNET era manter os ex-alunos da instituição, os docentes e os profissionais da área da saúde, informados das atualizações científicas. Ou seja, havia uma preocupação para com o processo, com a comunicação, uma preocupação para que a informação chegasse aos interessados de forma eficiente. 


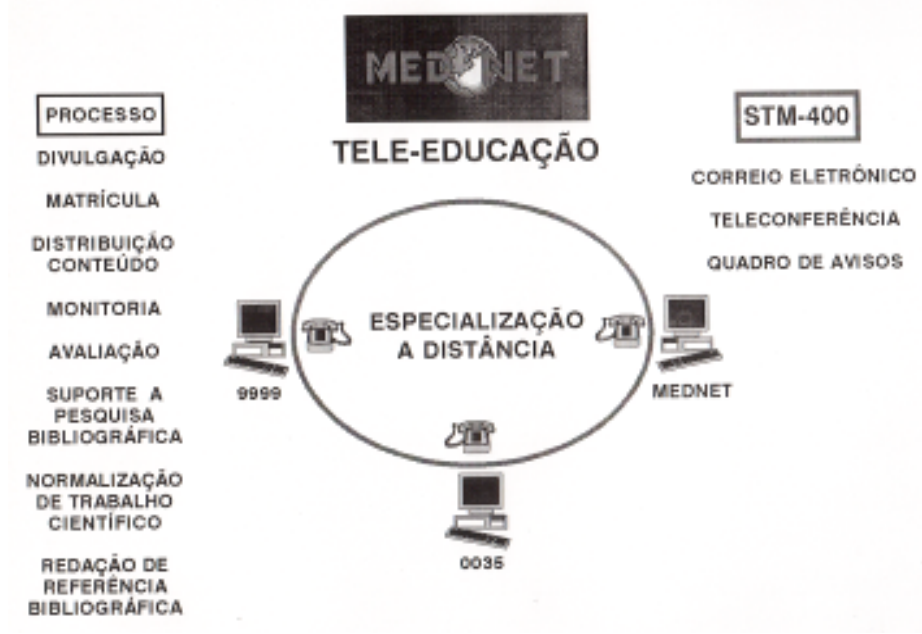

Figura 1. Esquema de serviços oferecidos pela MEDNET

Fonte: Acervo documental Neti/UFTM

O mais interessante a ser observado na estruturação deste projeto, como a própria Silva destacou em seu depoimento, é que a ideia de compartilhamento precedia a Internet que temos hoje (Figura 1). A Rede MEDNET dispunha dos seguintes serviços: correio eletrônico, jornal eletrônico, quadro de avisos, sumário de periódicos, levantamento bibliográfico, cópia de documentos, teleconferências e consultoria profissional. Por mais que hoje tais recursos pareçam tão comuns em meio a tantas possibilidades que a internet dispõe, no contexto da época, o projeto se destacava como inovador no sentido de facilitador para o compartilhamento de informações.

Embora fosse algo que surgiu para facilitar, a própria linguagem computacional utilizada para o funcionamento da rede não era simples ou de fácil assimilação, ao contrário, como podemos ver na Figura 2.

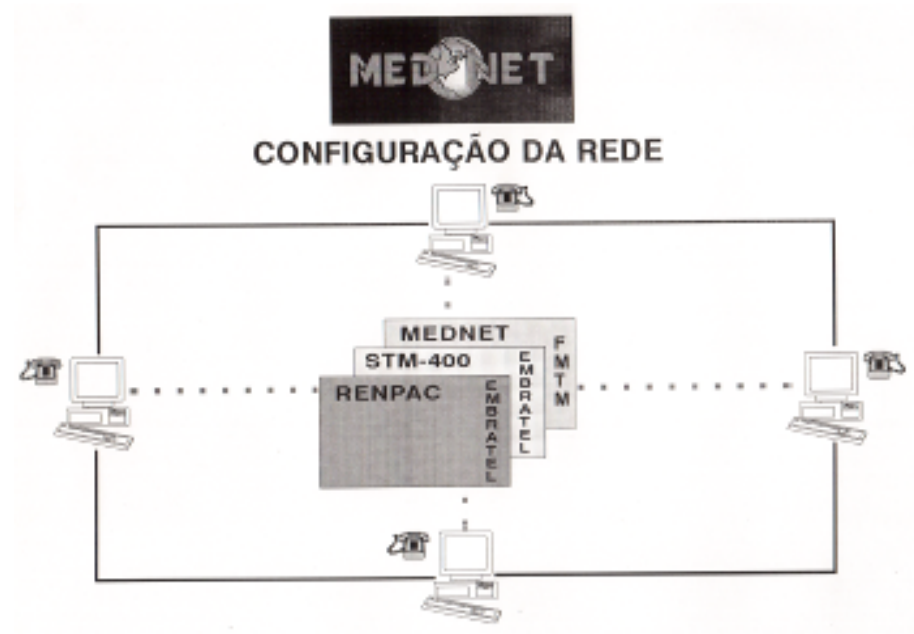


Figura 2. Esquema configuração da Rede MEDNET

Fonte: Acervo documental Neti/UFTM

É importante lembrar que foi em 1988 na Universidade de São Paulo que a ideia de estabelecer contatos com instituições de outros países foi desenvolvida e que mais tarde veio a se concretizar com a chegada ao Brasil da Bitnet (Because it's time to Network). Este serviço foi inaugurado oficialmente em 1989 e ligava a Fapesp, Fundação de Amparo a Pesquisa de São Paulo, ao Fermilap, laboratório de Física de Altas Energias de Chicago (EUA). Em 1991, o acesso ao sistema foi liberado e deu-se o nome internet. A internet era reservada a um número muito reduzido de pessoas e era usada para a transferência de arquivos e softwares, assim como também para fóruns de debates e acesso a base de dados nacionais e internacionais. Em 1992 o uso da internet foi liberado para as ONGs e em 1993 ocorreu a primeira conexão de 64 kbps à longa distância, estabelecida entre São Paulo e Porto Alegre. Em 1994, estudantes da USP criaram várias páginas na Internet (PRATALINHARES, 2008).

Percebe-se assim que neste mesmo período a FMTM estava na vanguarda de um sistema inovador de transmissão e compartilhamento de informações.

Silva ainda informou em seu depoimento que a instituição aderiu ao email institucional em 31/07/1998, com domínio @fmtm.br. Em 24/08/2004 passou a ser obrigatório o domínio @fmtm.edu.br, por norma da Fundação de Amparo à Pesquisa do Estado de São Paulo (FAPESP), e quando a Faculdade de Medicina do Triângulo Mineiro passou a ser Universidade Federal do Triângulo Mineiro, em 2006, o domínio passou a ser @uftm.edu.br.

Passados 12 anos desde a implantação do e-mail institucional, em março de 2010 é criado na UFTM o NATIC, Núcleo de Aprendizagem com Tecnologias de Informação e Comunicação, que em dezembro de 2010 se transforma em Centro de Educação a Distância (CEAD)

formado por professores que atuam na graduação e pós graduação e técnicosadministrativos. Tem o propósito de atender a demanda, através de estudos, pesquisas e projetos, do uso de tecnologias digitais de informação e comunicação na educação, mediante suporte especializado nas esferas do ensino, pesquisa e extensão $0^{\text {iii. }}$.

A criação do CEAD surge de forma a implementar a EAD na instituição, mediando as mudanças no contexto educacional permeado pelas TIC, bem como prestar orientações pedagógicas nesse sentido, executando projetos educacionais usando tecnologias digitais 
de informação e comunicação e colaborar na criação de cursos na modalidade a distância dentro da instituição.

Após a implantação do CEAD na instituição, foi implantado o ambiente virtual de aprendizagem (AVA) Moodle, que é um software livre e na época bastante utilizado nas instituições de ensino superior por ter o código aberto e por ser gratuito.

O Moodle é um Course Management System (CMS), também conhecido como Learning Management System (LMS) ou Ambiente Virtual de Aprendizagem (AVA). Ele é um aplicativo web gratuito que os educadores podem utilizar na criação de sites de aprendizado eficazes ${ }^{\text {iv }}$.

A implantação do AVA na UFTM aconteceu em dezembro de 2010 e nos 2 anos seguintes o número de usuários aumentou gradativamente, como se observa no Gráfico 1, o que mostra que houve um interesse da comunidade acadêmica por esse ambiente virtual de aprendizagem.

Gráfico 1. Evolução do número de usuários no Moodle

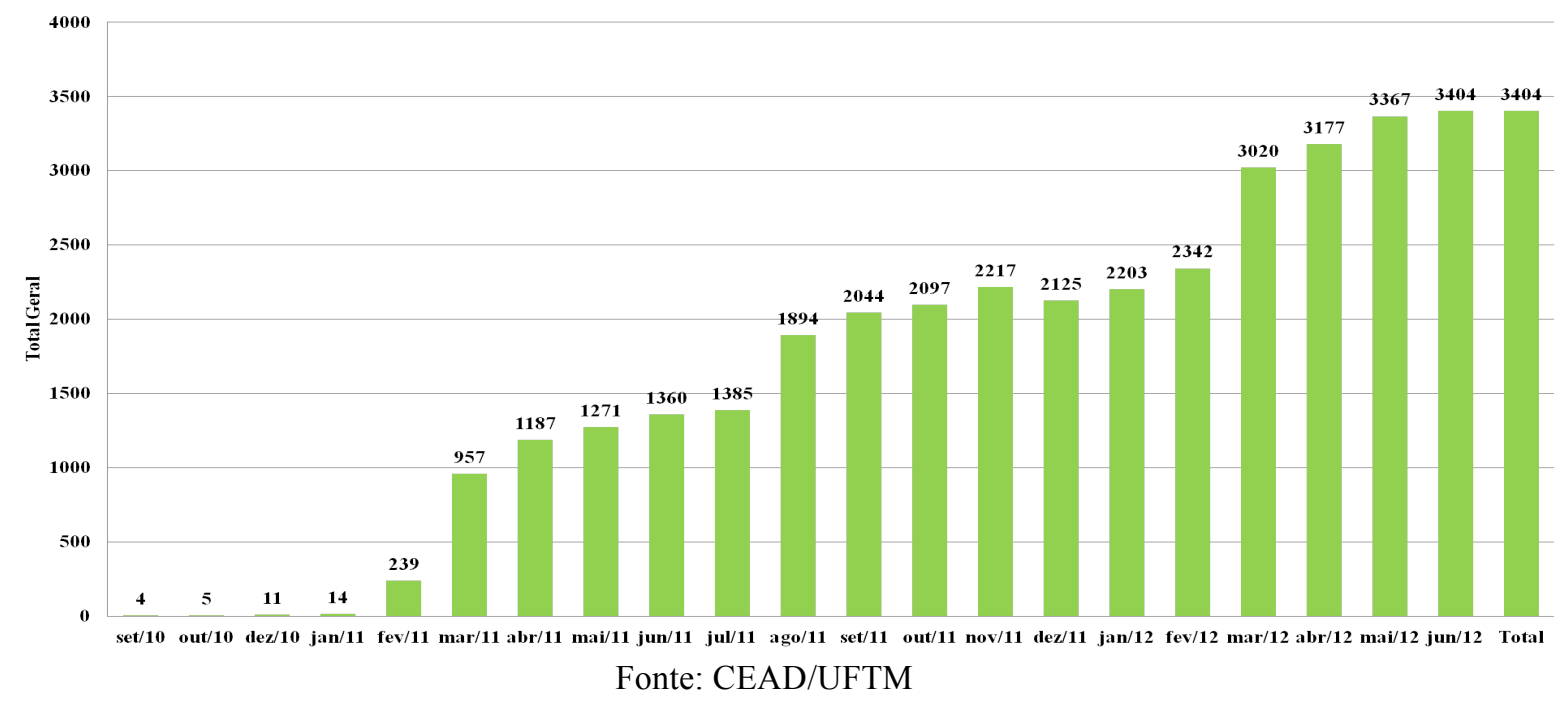

\section{A Web 2.0 e a Educação a Distância}

$\mathrm{O}$ advento da internet e as TIC surgiram na sociedade e foram colocadas à serviço da EAD no contexto mundial. A Web 2.0, possibilitando interação via TIC, surgiu como possibilidades para uma proposta mais abrangente ainda, por possibilitar justamente a interação e a construção mútua entre professores e alunos. Dentro da Web 2.0, estão as redes sociais, que permitem interação e ao mesmo tempo produção por ambas as partes que se interagem. 
Para o levantamento de dados da pesquisa, optou-se por aplicação de questionários com os docentes da universidade, bem como analisar os projetos político-pedagógicos dos cursos e os planos de ensino das disciplina no período de 2010 a 2012.

Em um primeiro momento, a pesquisa foi realizada ao final de 2010 e foram aplicados 238 questionários aos docentes universitários participantes. Dos dados obtidos e analisados, o que foi apontado é que apenas uma pequena parcela dos docentes utilizavam as redes sociais disponíveis na internet no contexto pedagógico em si ou seja, relação professor-aluno, sendo que a maioria utilizava apenas para fins pessoais (Gráfico 2). 
Gráfico 2. Aplicativos da internet utilizados pelo professor para fins pessoais

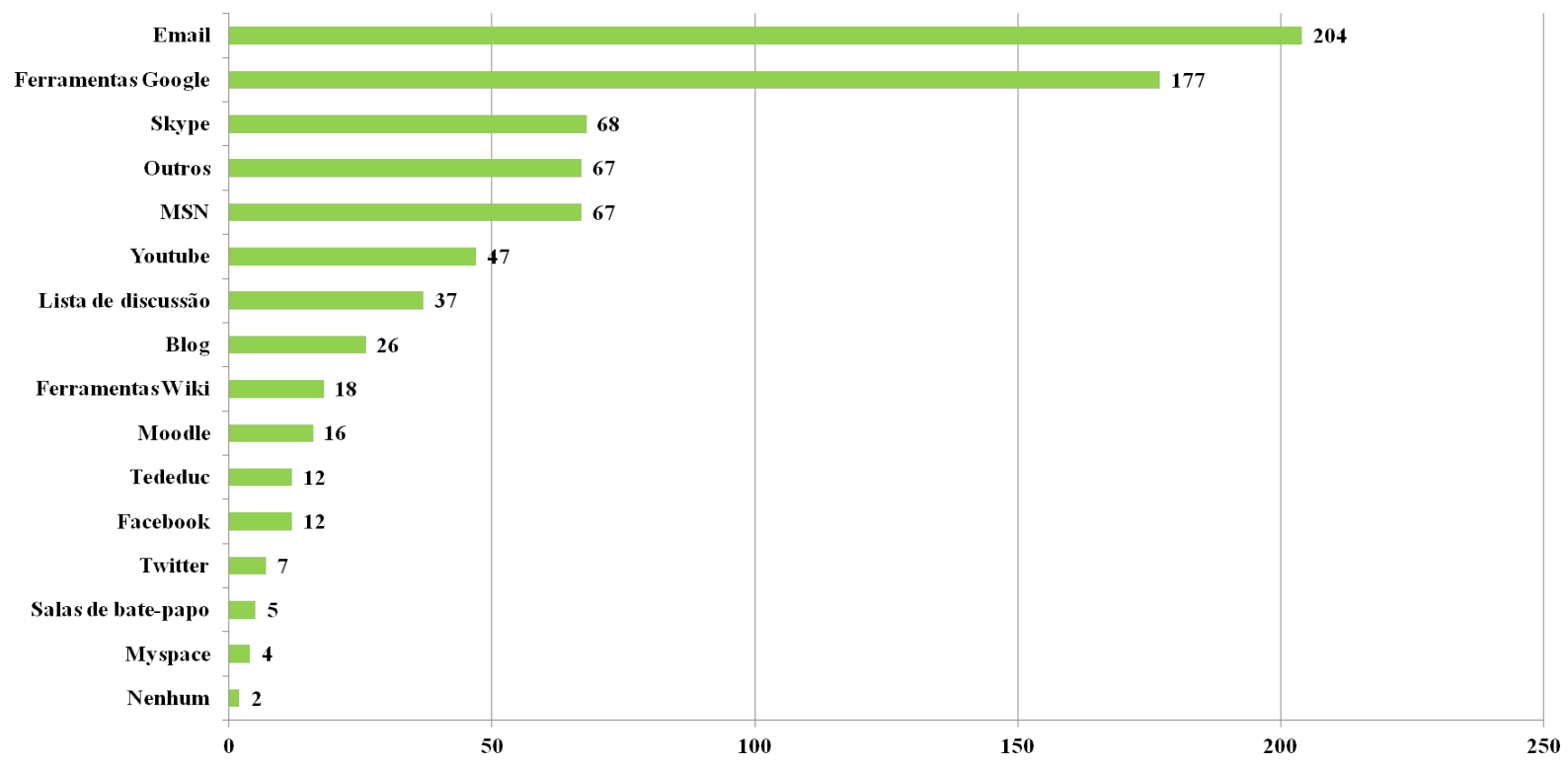

Dentre as tecnologias digitais que foram listadas no questionário, o correio eletrônico (email) e as ferramentas Google se destacam no que se refere ao uso pessoal do professor (Gráfico 2). Todavia, como se observa no Gráfico 3, o email continua se destacando na relação professor-aluno, porém há uma diminuição no uso das ferramentas Google na relação professor-aluno, sendo que dos 188 professores que utilizam estas tecnologias para fins pessoais, apenas 71 fazem uso dos recursos nessa relação entre professor e aluno.

Gráfico 3. Aplicativos utilizados na relação professor-aluno

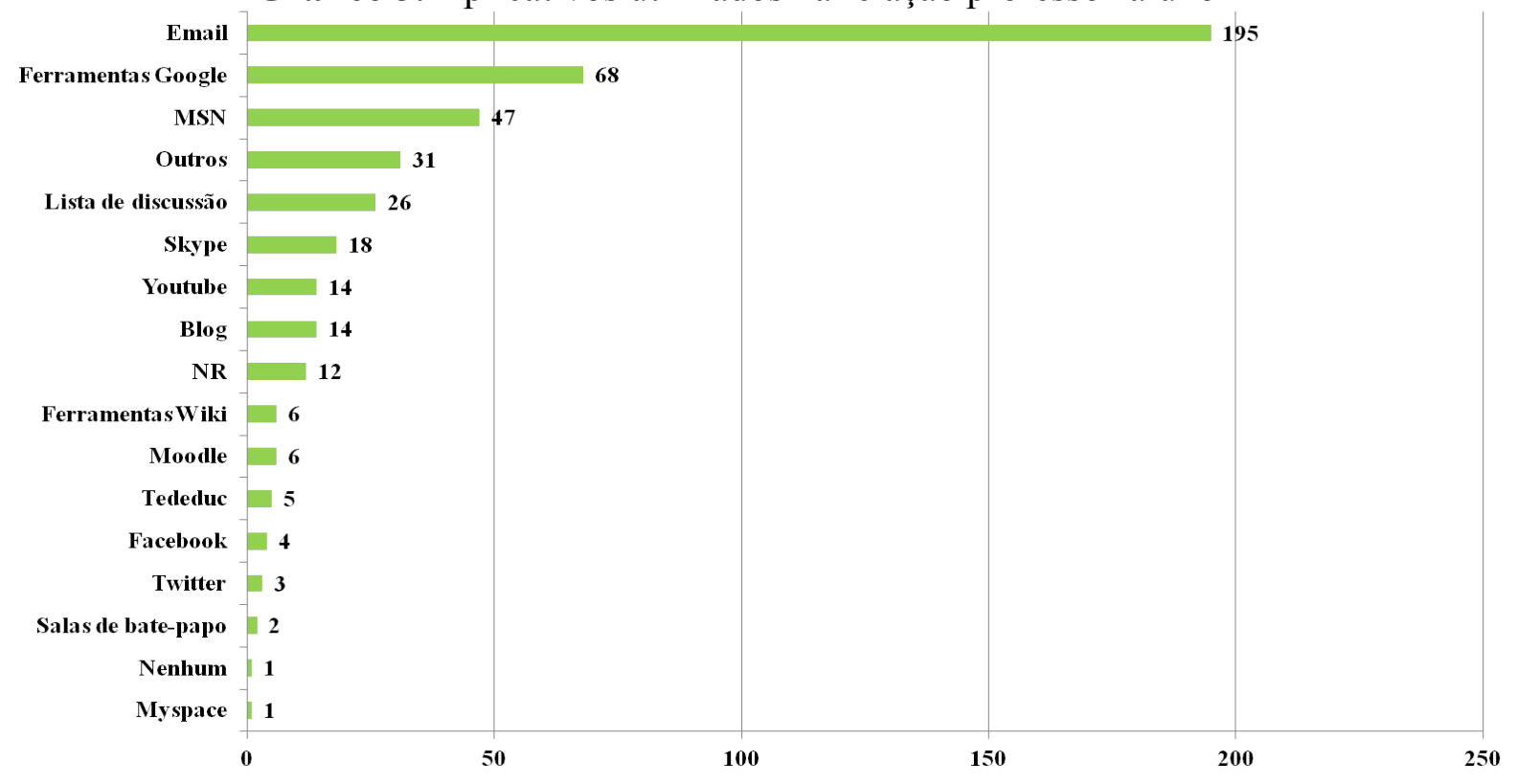


Essa redução no uso aconteceu também com outros aplicativos utilizados para fins diversos pelos professores quando questionados se os usavam na relação professor-aluno, como o MSN que teve uma diferença de quase 10\% e o Skype que se difere em aproximadamente $23 \%$ se comparado ao uso para fins pessoais.

Interessante ressaltar que, caso esse questionário fosse repetido 2 ou 3 anos depois, certamente os indicativos apontariam para uma nova realidade. As redes sociais virtuais, como Facebook e Twitter, teriam um número maior e mais significativo de seus usos, pois, após a aplicação deste questionário houve uma ascensão do uso dessas redes sociais e estão sendo cada vez mais constituintes do cotidiano, e isso tem tido reflexo dentro da universidade.

Além da aplicação dos questionários, em 2011 foram analisados 24 projetos político-pedagógicos (PPP) de cursos da instituição com o objetivo de verificar se esses cursos faziam uso das TIC e de que forma mencionava-se nos documentos que elas eram usadas.

Os Projetos Pedagógicos analisados foram elaborados de acordo com um guia de orientações gerais disponibilizado na época pela UFTM, que depois foi transformado no Guia de Orientações Gerais para Elaboração dos Projetos Pedagógicos dos Cursos de Graduação da UFTM (2011). O guia traz um item para o curso escrever como se dá o processo de incorporação das novas tecnologias educacionais ao ensino de graduação.

Das análises realizadas destaca-se alguns aspectos listados abaixo, destacando os cursos de graduação dos mais antigos para os mais novos.

Os Projetos Pedagógicos dos Cursos de Graduação em Biomedicina, Enfermagem e Terapia Ocupacional contemplam o desenvolvimento de competências e habilidades para domínio das tecnologias de comunicação e informação e/ou o uso adequado das novas tecnologias, tanto de informação quanto de comunicação.

Os Cursos de Bacharelado em Biomedicina, Enfermagem, Medicina, Nutrição, Terapia Ocupacional, Fisioterapia, Psicologia e Educação Física e o Curso de Licenciatura em Letras trazem nas matrizes curriculares a oferta de componentes curriculares obrigatórios, eletivos ou optativos relacionados ao uso das tecnologias tais como: Informática, Informática Aplicada à Saúde, As Linguagens e as Tecnologias da Informação, dentre outros.

No mesmo sentido, os Cursos de Licenciaturas em Ciências Biológicas, Química, Física, Matemática, História, Geografia e Serviço Social implantados no ano de 2009, 
ofertam componente curricular relacionado ao Uso das Tecnologias da Informação e Comunicação das áreas específicas, e ainda, disponibiliza o componente curricular eletivo Comunicação, Educação e Tecnologias cuja ementa trata das tecnologias de mídia, códigos e linguagens; leitura e apropriação de mensagens midiáticas e tecnologias e inclusão digital.

Os Projetos Pedagógicos dos Cursos de Engenharias implantados em 2010, contemplam o componente curricular obrigatório para todos os cursos denominado Programação Computacional com carga horária de 120h/a e, ainda, um componente curricular eletivo relacionado às Novas Tecnologias, Normas, Métodos e sua Implementação na Engenharia.

É importante destacar que os Projetos Pedagógicos analisados no período de 20102012 apontam a necessidade da UFTM disponibilizar a infraestrutura física adequada com computadores, softwares, internet, bem como, a necessidade de se ter um ambiente virtual de aprendizagem.

No entanto, numa análise geral percebe-se que os cursos mencionam a preocupação com a formação do aluno para o uso das tecnologias em seus respectivos cursos, porém como no período 2010- 2012 a UFTM ainda era uma universidade muito nova, com nem 10 anos de existência, advinda do processo de transformação em 2005, de Faculdade isolada para Universidade, encontrava-se ainda em processo intermediário de passagem de um ensino mais conservador para a busca de uma perspectiva mais inovadora de ensino.

As análises dos Projetos Pedagógicos mostraram que ainda era grande o desafio do uso das tecnologias da informação e comunicação pelos cursos da UFTM como se pode inferir do texto do Projeto Pedagógico do Curso de Física:

O uso de TICs no ensino de Física e também no TCC comprovam a nossa
disposição de experimentar e propor projetos com o objetivo de dotar a
institução de uma estrutura mínima para que permita, num futuro próximo,
utilizar, por exemplo ambientes virtuais de aprendizagem com uma das
possibilidades educativas. Pensando nisso foi criado na instituição o Núcleo de
Aprendizagem em Tecnologias da Informação - NATIC, que tem como objetivo
promover ações que atenda às necessidades de incorporação das novas
tecnologias nos cursos (UFTM, 2010).

Percebe-se que a então "jovem UFTM" precisava continuar o debate sobre a educação de qualidade, não esquecendo que a construção do conhecimento deve ocorrer na sociedade da informação que demanda novas formas de aprendizagem, revisão de 
papéis e formação permanente dos professores e alunos no contexto dos avanços das tecnologias de informação e comunicação.

Cabe aqui salientar, que ao construir o Projeto Pedagógico do Curso o grupo de docentes responsável por sua elaboração planejava o que tinha intenção de buscar, realizava com vistas a qualidade do curso como um todo. Porém, nem sempre o que está planejado é possível de ser concretizado, fazendo com que muito do que estava retratado no projeto pedagógico não fosse realizado.

Por outro lado, ao constituir-se como processo, colocando em prática o currículo proposto, eram desenvolvidas por docentes e discentes atividades acadêmicas que iam além do que estava escrito no Projeto Pedagógico do Curso.

Num levantamento realizado após análise de 680 planos de ensino do primeiro semestre de 2012, foi perceptível a mudança entre as análises feitas aos documentos do ano anterior. Dos 680 planos analisados, 143 mencionam as TIC em alguma parte do plano, sendo mais comum aparecer no item Estratégias/Recursos, seguido pelos itens Ementa, Avaliação, em que 8 planos preveem avaliações que utilizem as TIC e, por último, nos Objetivos. Porém, não há descrição de quais TIC serão utilizadas, há uma generalização na menção do uso da "internet" de uma maneira mais abrangente, podendo ser apenas utilizada para busca.

Outro fator importante, que pode ser motivo pelo não uso dessas possibilidades é o uso do Moodle, que também apresentaria diferença significativa na pesquisa, caso reaplicada, pois, como foi dito, a implantação do Moodle aconteceu ao final de 2010, período em que se realizou-se essa pesquisa, ou seja, era algo muito embrionário, sendo que em dezembro de 2012 chegou a 3912 usuários na plataforma.

Entretanto, a plataforma Moodle ao mesmo tempo em que tem um rol de possibilidades, como aplicação de questionários, criação de grupos dentro da plataforma, ela parece limitar por seu design e pela falta de formação para seu uso, o que muitas vezes se torna apenas repositório e suas possibilidades de interação são pouco aproveitadas.

Todavia, como foi dito anteriormente, quando se trata do uso do Moodle, no primeiro levantamento realizado, notou-se que disciplinas de conhecimento específico ainda não haviam aderido a essa possibilidade de flexibilidade de carga horária, ocorrendo apenas em disciplinas comuns a todos os cursos como Estudo e Desenvolvimento de Projetos (EDP), Metodologia Científica e Trabalho de Conclusão de Curso (TCC). Assim, 
o aumento gradativo do número de usuários na plataforma Moodle nos 2 primeiros anos de implantação sugere a anexação de práticas pedagógicas a distância no ensino presencial.

Entretanto, apesar do número de usuários registrados no Moodle no ano de 2012, o número de planos que mencionam o uso do Moodle não é proporcional ao número de usuários da plataforma. Em 2012 há um número bastante considerável de disciplinas cadastradas na plataforma, que são 154, e apenas 10 planos que preveem o uso, sendo que, destes 10 , apenas 1 faz menção aos $20 \%$ a distância.

Uma hipótese que pode ser levantada é que os docentes ainda estavam experimentando e se adaptando a esta nova forma de ensinar e aprender para depois concretizarem nos documentos oficiais, como o plano de ensino das disciplinas.

\section{CONSIDERAÇÕES FINAIS}

Após as análises dos dados e leituras teóricas, o que se percebe é que a instituição durante os dois primeiros anos de implantação do AVA estava aos poucos assimilando as novas possibilidades de ensino e aprendizagem, apesar de ser algo pouco perceptível se comparado ao movimento que ocorreu na instituição em 1988 para inserção de um sistema que integrasse e mantivesse atualizados os ex-alunos. Uma questão que pode vir a justificar a lenta inserção das TIC e, por consequência, os $20 \%$ a distância, é a questão da falta de infraestrutura na instituição no período pesquisado.

Do que pôde ser observado é que o uso das TIC bem como as redes sociais virtuais no contexto educacional da instituição pesquisada no período de 2010 a 2012 estava ainda distante do contexto dos alunos, que em grande parte já eram nativos digitais, fazendo com que aluno e instituição se distanciassem, ao menos aparentemente, da realidade, aqui considerando as TIC como parte da realidade desses alunos.

A pesquisa mostrou que a chegada do ambiente virtual de aprendizagem na instituição despertou interesse nos docentes e discentes. Porém, uma tecnologia nova pode trazer promessas de inovação, mas como toda "novidade", é preciso investir em uma política institucional de fomento que impulsione o desenvolvimento para o uso significativo e com qualidade das tecnologias digitais, objetivando a aprendizagem e consequentemente o desenvolvimento dos envolvidos nesse processo. 


\section{Referências}

AGHAEI, Sareh; NEMATBAKHSH, Mohammad Ali; FARSANI, Hadi Khosravi. Evolution of the World Wide Web: from Web 1.0 to Web 4.0. International Journal of Web \& Semantic Technology (IJWesT). v. 3, n. 1, jan 2012. Disponível em: < http://airccse.org/journal/ijwest/papers/3112ijwest01.pdf> Acesso em 04 nov. 2012.

ALVES, João Roberto Moreira. A história da EAD no Brasil. In: LITTO, Frederic Michael; FORMIGA, Manuel Marcos Maciel. (Org.) Educação a Distância: o estado da arte. São Paulo, SP: Pearson Education do Brasil, 2009.

BRASIL. Presidência da República. Decreto 5.622, de 19 de dezembro de 2005. Regulamenta o art. 80 da Lei no 9.394, de 20 de dezembro de 1996, que estabelece as diretrizes e bases da educação nacional. Diário Oficial [da] República Federativa do Brasil, Poder Executivo, Brasília, DF, 19 dez. 2005. Disponível em: $<$ http://www.planalto.gov.br/ccivil_03/_Ato2004-

2006/2005/Decreto/D5622.htm>. Acesso em: 06 abr. 2012.

CARLINI, Alda Luiza; TARCIA, Rita Maria Lino (Org.). 20\% a distância: e agora?. São Paulo, SP: Pearson, 2010.

FARIAS, Giovani. O tripé regulador da EAD no Brasil. In: SILVA, Marco. Educação Online. 3.ed. São Paulo: Loyola, 2011.

HARASIM, Linda; TELES, Lucio; TUROFF, Murray; HILTZ, Starr R. Redes de aprendizagem: Um guia para ensino e aprendizagem on-line. São Paulo: Senac, 2005.

KENSKY, Vani Moreira. Tecnologias e Ensino Presencial e a Distância. 5. ed. Campinas, SP: Papirus, 2012.

LEVY, Pierre. A inteligência coletiva. São Paulo: Edições Loyola, 1998.

LOBO NETO, Francisco José da Silveira. Regulamentação da educação a distância: caminhos e descaminhos. In: SILVA, Marco. Educação Online. 3.ed. São Paulo: Loyola, 2011.

MAIA, Carmen; MATTAR, João. ABC da EaD: A Educação a Distância de Hoje. São Paulo, SP: Pearson. 2007.

MASETTO, Marcos (Org.). Docência na Universidade. 11.ed. Campinas, SP: Papirus, 1998.

MASETTO, Marcos. Inovação na Educação Superior. Revista Interface - Comunic., Saúde, Educ., v.8, n.14, p.197-202, set.2003-fev.2004

MATTAR, João. Web 2.0 e Redes Sociais na Educação a Distância: cases no Brasil. La Educ@cion. OAS, n. 145, maio 2011. Disponível em: < http://www.educoea.org/portal/La_Educacion_Digital/laeducacion_145/index.html> Acesso em 06 set. 2011. 
MINISTÉRIO DA EDUCAÇÃO. Portaria n. ${ }^{\circ} 4.059$, de 10 de dezembro de 2004.

MORAN, José Manuel. A Educação que Desejamos: novos desafios e como chegar lá. 5.ed. Campinas, SP: Papirus, 2007.

. Novos caminhos do ensino a distância. Informe CEAD - Centro de Educação a Distância. SENAI, Rio de Janeiro, ano 1, n.5, out/dez de 1994, páginas 1-3.

MOVAREC, John. Moving beyond education 2.0. Education Futures. Fev. 2008. Disponível em: $<$ http://www.educationfutures.com/2008/02/15/moving-beyond-education20/> Acesso em 04 nov. 2012.

NUNES, Ivônio Barros. A história da EAD no mundo. In: LITTO, Frederic Michael; FORMIGA, Manuel Marcos Maciel. (Org.) Educação a Distância: o estado da arte. São Paulo, SP: Pearson Education do Brasil, 2009.

PRATA-LINHARES, Martha Maria. Arte na formação pedagógica de professores do ensino superior. Tese. São Paulo: Programa de Pós-Graduação em Educação: Currículo, da Pontifícia Universidade Católica de São Paulo, 2008, 199p.

. O professor e a formação de professores. In: SOUZA, Ruth Catarina Cerqueira Ribeiro de; MAGALHÃES, Solange Martins Oliveira (Org.). Professores e professoras: formação: poiésis e práxis. Goiânia, GO: Ed. da PUC Goiás, 2011, p. 99-113.

A Inovação e o Uso das TIC na Educação. In: SANTOS, Gilberto Lacerda; GALÁN, José Goméz (Org.). Informática e Telemática na Educação. Brasília, DF: Liber Livro, 2012.

PRESKY, Marc. Digital Natives, Digital Immigrants. MCB University Press, v.9, n. 5, 2001.

SILVA, Dalva. Uberaba. Entrevista concedida a Diogo S. Chagas. 2012.

SOALHEIROS, Bárbara. Como fazíamos sem. São Paulo: Books, 2006.

SOUZA, Ruth Catarina Cerqueira Ribeiro de; GUIMARÃES, Valter Soares. Docência e Identidade profissional do professor. In: SOUZA, Ruth Catarina Cerqueira Ribeiro de; MAGALHẪES, Solange Martins Oliveira (Org.). Professores e professoras: formação: poiésis e práxis. Goiânia, GO: Ed. da PUC Goiás, 2011, p. 25-41.

UNIVERSIDADE FEDERAL DO TRIÂNGULO MINEIRO. Projeto Pedagógico do Curso de Física da Universidade Federal do Triângulo Mineiro, UFTM, Uberaba, 2010.

. Guia de Orientações Gerais para Elaboração dos Projetos Pedagógicos dos Cursos de Graduação da UFTM. Elaborado pelo Núcleo de Desenvolvimento Educacional, NuDE, da Universidade Federal do Triângulo Mineiro, UFTM, Uberaba, 2011. 
VALENTE, José Armando. O "estar junto virtual" como uma abordagem de Educação a Distância In: _ ; BUSTAMANTE, Silvia Branco Vidal (Org.). Educação a Distância: Prática e formação do profissional reflexivo. São Paulo, SP: Avercamp, 2009.

WERTHEIN, Jorge. A sociedade da informação e seus desafios. Ci. Inf., Brasília, v. 29, n. 2, maio/ago, p. 71-77, 2000.

\section{RECEBIDO EM: 02/12/2015.} APROVADO EM: 23/02/2016.

Agências de financiamento: FAPEMIG; FUNEPU e CNPq.

\footnotetext{
${ }^{\mathrm{i}}$ O buscador Google é um serviço da empresa Google Inc. que serve como ferramenta para pesquisa na internet por qualquer assunto ou conteúdo. - http://www.google.com.br/

ii Os termos "nativos digitais" e "imigrantes digitais" são traduções dos termos originais "digital natives" e "digital immigrants"

iii Retirado do site do CEAD/UFTM - http://uftm.edu.br/cead/. Acesso em: 24 abr. 2012.

${ }^{\text {iv }}$ Retirado do site oficial da Plataforma Moodle - http://moodle.org/. Acesso em: 26 jul. 2012
} 